\title{
Vitamin D induces myogenic differentiation in skeletal muscle derived stem cells
}

\author{
Melissa Braga', Zena Simmons ${ }^{2}$, Keith C Norris ${ }^{3}$, Monica G Ferrini ${ }^{1,2,3}$ and \\ Jorge N Artaza ${ }^{1,2,3}$
}

'Department of Internal Medicine, Charles R. Drew University of Medicine and Science, Los Angeles, California, USA

${ }^{2}$ Department of Health \& Life Sciences, Charles R. Drew University of Medicine and Science, Los Angeles, California, USA

${ }^{3}$ Department of Medicine, David Geffen School of Medicine at UCLA, Los Angeles, California, USA

\author{
Correspondence \\ should be addressed \\ to J N Artaza \\ Email \\ joartaza@ucla.edu
}

\begin{abstract}
Skeletal muscle wasting is a serious disorder associated with health conditions such as aging, chronic kidney disease and AIDS. Vitamin D is most widely recognized for its regulation of calcium and phosphate homeostasis in relation to bone development and maintenance. Recently, vitamin D supplementation has been shown to improve muscle performance and reduce the risk of falls in vitamin D deficient older adults. However, little is known of the underlying molecular mechanism(s) or the role it plays in myogenic differentiation. We examined the effect of $1,25-D_{3}$ on myogenic cell differentiation in skeletal muscle derived stem cells. Primary cultures of skeletal muscle satellite cells were isolated from the tibialis anterior, soleus and gastrocnemius muscles of 8-week-old C57/BL6 male mice and then treated with 1,25- $\mathrm{D}_{3}$. The efficiency of satellite cells isolation determined by PAX7+ cells was $81 \%$, and they expressed VDR. Incubation of satellite cells with 1,25- $D_{3}$ induces increased expression of: (i) MYOD, (ii) MYOG, (iii) MYC2, (iv) skeletal muscle fast troponin I and T, (v) MYH1, (vi) IGF1 and 2, (vii) FGF1 and 2, (viii) BMP4, (ix) MMP9 and (x) FST. It also promotes myotube formation and decreases the expression of MSTN. In conclusion, 1,25- $D_{3}$ promoted a robust myogenic effect on satellite cells responsible for the regeneration of muscle after injury or muscle waste. This study provides a mechanistic justification for vitamin D supplementation in conditions characterized by loss of muscle mass and also in vitamin D deficient older adults with reduced muscle mass and strength, and increased risk of falls.
\end{abstract}

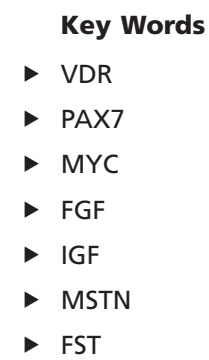

Endocrine Connections (2017) 6, 139-150

\section{Introduction}

Vitamin D is universally recognized for its classical effects on calcium regulation and phosphate homeostasis, in relation to bone development and maintenance $(1,2)$. However, vitamin D deficiency has also been linked to the pathogenesis of several acute and chronic diseases such as musculoskeletal disorders, especially associated with reduced muscle mass and impaired physical performance in frail and elderly individuals $(3,4)$. While vitamin D deficiency has been associated with a reduction in upper and lower limb muscle strength and physical performance (5), a positive association between vitamin D supplementation on upper and lower body muscle strength has been described in healthy individuals (6).

At a cellular level there is also evidence of VDR expression and direct effects of vitamin $\mathrm{D}$ on human skeletal muscle precursor cells (7), which provides a (c) 2017 The authors Published by Bioscientifica Ltd http://www.endocrineconnections.org DOI: 10.1530/EC-17-0008

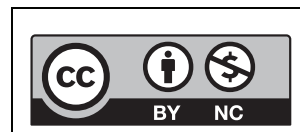

This work is licensed under a Creative Commons Attribution-NonCommercial 4.0 International License. 
rationale for a direct role of vitamin $\mathrm{D}$ in muscle function. Furthermore, mice lacking VDR show an abnormal skeletal muscle phenotype with smaller, variable muscle fibers and persistence of immature muscle gene expression during adult life, suggesting a role of vitamin D in muscle development $(8,9)$. However, more research needs to be done in order to decipher the underlying mechanism or the role vitamin D plays in association with myogenic differentiation. Vitamin $\mathrm{D}$, a fat-soluble secosteroid prohormone, is obtained from sun exposure or from dietary sources. During exposure to sunlight 7-dehydrocholesterol in the skin is converted to previtamin D3, which is immediately converted by a heatdependent process to vitamin D3. Vitamin D2 and vitamin D3 from dietary sources are incorporated into chylomicrons and transported by the lymphatic system into the venous circulation. Vitamin D in the circulation is bound to the vitamin D-binding protein, which transports it to the liver, where the enzyme, D-25 hydroxylase, converts vitamin $\mathrm{D}$ to 25 -hydroxyvitamin D3. 25-HydroxyvitaminD $\mathrm{D}_{3}$ is biologically inactive and is converted primarily in the kidney by the 25-hydroxyvitamin D-1-hydroxylase to its biologically active form 1,25-D3 or calcitriol (10). Our group and others have previously delineated the role of vitamin $\mathrm{D}$ in myogenic cell differentiation in C2C12 cells $(11,12$, 13, 14). Mouse C2C12 skeletal muscle myoblast cells are an 'in vitro' cell line, which is widely used to study genes that regulate muscle growth and differentiation $(15,16)$.

Satellite cells, also known as 'skeletal muscle stem cells', have a remarkable ability to regenerate after muscle injury and are responsible for compensation of muscle turnover caused by daily wear and tear. In this study, we expand our previous results and conclusions $(11,12)$ by now utilizing a more clinically relevant cell model, which is the primary culture of skeletal muscle derived satellite cells. In conclusion, the aim of the present study was to test the hypothesis that $1,25-\mathrm{D}_{3}$ promotes myogenic cell differentiation by targeting skeletal muscle stem cells, and to determine the associated molecular mechanism(s). This was done by investigating the expression of key proand anti-cell differentiation lineage markers and select growth factors modulated by $1,25-\mathrm{D}_{3}$ in primary cultures of skeletal muscle satellite cells.

\section{Materials and methods}

\section{Experimental animals}

Male 8-week-old C57/BL6 mice (B.W.: 22.0 $\pm 0.3 \mathrm{~g}$ ) from Jackson Laboratories were used for this study, which was approved by the Institutional Animal Care and Use Committee (IACUC) at Charles R. Drew University of Medicine and Science. Mice were housed for one week prior to experimental procedures to permit acclimatization. Animals were killed by $\mathrm{CO}_{2}$ inhalation. After confirming the death of the animals, they were soaked in alcohol 70\% for $5 \mathrm{~min}$. The skin and fascia were then removed and the hind limb muscles tibialis, soleus and gastrocnemius were removed under aseptic conditions. Later we proceeded with the satellite cells isolation.

\section{Cell culture and satellite cell isolation}

Primary satellite cell cultures were isolated as previously described $(17,18)$. Briefly, once tendons, vessels and fat were removed, each muscle was cut into small fragments and enzymatically digested at $37^{\circ} \mathrm{C}$ in $0.2 \%$ collagenase solution for $1 \mathrm{~h}$. Myofibers were further purified from interstitial cells and tendons by a series of trituration, sedimentation and washings. Myofiber fragments were passed through a $40-\mu \mathrm{m}$ cell strainer, resuspended in growth media (DMEM medium containing 20\% FBS, $10 \%$ horse serum and 1\% chick embryo extract) and plated in culture dishes. Cells were allowed to adhere for $2 \mathrm{~h}$ to remove large debris, macrophages and fibroblasts that adhere to the plastic. The primary non-attached myoblasts were transferred onto collagen-coated T25 flask and left undisturbed for 3 days allowing the cells to attach. Upon reaching 70\% confluency, the satellite cells were detached and replated according to different treatments. Cells were incubated with or without $100 \mathrm{nM} 1,25-\mathrm{D}_{3}$ (Sigma-Aldrich) dissolved in less than $0.1 \%$ ethanol as vehicle in growth media for 1-12 days. The $100 \mathrm{nM}$ supraphysiological concentration of $1,25-\mathrm{D}_{3}$ employed in the experimental designed was the optimal concentration established based on our prior dose-response studies $(21,22)$ and it is in alignment with a commonly used dose applied in the majority of publications related to $1,25-\mathrm{D}_{3}$ effects on different cell lines or in primary cell cultures (19-24). Because of the 10-h half-life of $1,25-\mathrm{D}_{3}$, the cell culture media, incubated with or without 1,25-D3 $(100 \mathrm{nM})$, was replaced daily $(11,12)$.

\section{Detection of PAX7, VDR and MYC by immunocytochemistry}

Satellite cells incubated in growth media for 1 day in collagen-coated chamber slides were washed thrice with PBS (1x) and fixed by immersion in $2 \% p$-formaldehyde.

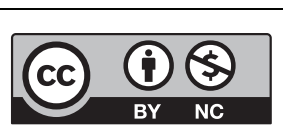
This work is licensed under a Creative Commons
Attribution-NonCommercial 4.0 International License. 
Cells were first quenched with $3 \% \mathrm{H}_{2} \mathrm{O}_{2}$ and then blocked with normal goat or horse serum, and incubated with: (1) a rabbit polyclonal antibody against PAX7 at a dilution of 1:200 (Abcam), (2) a rabbit polyclonal antibody against VDR at a dilution of 1:50 (Santa Cruz Biotechnology) or (3) a mouse monoclonal antibody against MYC type II (1:400) from Abcam. The detection was followed by a 1:200 dilution of either anti-rabbit or anti-horse biotinylated secondary antibody from Calbiochem, followed by the ABC complex (1:100) (Vectastain Elite ABC System, Vector Laboratories) and 3,3-diaminobenzidine (DAB) (Sigma), without counterstaining. In negative controls, we either omitted the first antibody or replaced it with a rabbit IgG isotype antibody (11).

\section{Double labeling immunofluorescence detection of PAX7 and VDR}

The double localization of PAX7 and VDR was carried out on $2 \% p$-formaldehyde-fixed satellite cells primary cultures plated on collagen-coated chamber slides. For VDR, cells were blocked with normal goat serum, and incubated with a rat monoclonal antibody against VDR at a dilution of 1:50 (Abcam), followed by a 1:200 dilution of anti-rat biotinylated secondary antibody (Vector Labs, Burlingame, CA, USA). The subsequent reaction was carried out by incubating the cells in a $20 \mathrm{mg} / \mathrm{mL}$ solution of streptavidin-FITC (Vector Labs), followed by $10 \%$ normal goat serum and then a 1:250 dilution of anti-PAX7 monoclonal antibodies (Abcam). Fluorescence labeling was performed with secondary antibody 'Texas Red' (13 mg/mL; Vector Labs). After several washes, the slides were detached and counterstained/mounted in 'vectashield' mounting medium with DAPI (Vector Labs). Slides were examined under a Leica DMLB fluorescence microscope equipped with the appropriate filters. The VDR/PAX7 co-localization images were obtained by merging the red and green filtered pictures, as well as the blue filter for the VDR/PAX7/DAPI merge. Fields were photographed with a Leica DFC310 FX digital camera and Leica acquisition software. Negative controls were done by either omitting the first antibody or using a rabbit non-specific IgG (25).

\section{PCR array analysis of skeletal muscle growth and differentiation factors}

$\mathrm{RT}^{2}$ profiler PCR pathway focused arrays (SABiosciences, Qiagen) were applied in triplicate in order to detect changes in gene expression of skeletal muscle growth and differentiation factors. Total cellular RNA from satellite cells that were treated with or without $1,25-\mathrm{D}_{3}(100 \mathrm{nM})$ for 7 days, was isolated with TRIzol Reagent (Invitrogen). They were then subjected to reverse transcription, and the resulting cDNA was analyzed by the Mouse Skeletal Muscle: Myogenesis \& Myopathy (PAMM-099Z) PCR Arrays (SABiosciences, Qiagen). The Mouse Skeletal Muscle: Myogenesis \& Myopathy $\mathrm{RT}^{2}$ Profiler $^{\mathrm{TM}}$ PCR Array contains genes related to skeletal muscle differentiation, function and disease-related processes. Real-time PCRs were performed as follows: melting for $10 \mathrm{~min}$ at $95^{\circ} \mathrm{C}$, 40 cycles of two-step PCR including melting for $15 \mathrm{~s}$ at $95^{\circ} \mathrm{C}$ and annealing for $1 \mathrm{~min}$ at $60^{\circ} \mathrm{C}$. The raw data was analyzed using the $C_{\mathrm{t}}$ method following the manufacturer's instructions (SABiosciences Corp., Qiagen) (26).

\section{Real-time quantitative PCR}

Total RNA was extracted using TRIzol Reagent (Invitrogen) and equal amounts $(1 \mu \mathrm{g})$ of RNA were reverse transcribed using High Capacity RNA-to-cDNA PCR kit (Applied Biosystems). Mouse gene PCR primer sets $\left(\mathrm{RT}^{2}\right)$ for VDR, IGF1, IGF2, FGF1, FGF2, MSTN and FST were obtained from SABiosciences. The Power SYBR green PCR Master Mix (Applied Biosystems) was used with Step-One-Plus real-time PCR System (Applied Biosystems). The protocol included melting for $15 \mathrm{~min}$ at $95^{\circ} \mathrm{C}, 40$ cycles of three-step PCR including melting for $15 \mathrm{~s}$ at $95^{\circ} \mathrm{C}$, annealing for $30 \mathrm{~s}$ at $58^{\circ} \mathrm{C}$, elongation for $30 \mathrm{~s}$ at $72^{\circ} \mathrm{C}$ with an additional detection step of $15 \mathrm{~s}$ at $81^{\circ} \mathrm{C}$, followed by a melting curve from 55 to $95^{\circ} \mathrm{C}$ at the rate of $0.5^{\circ} \mathrm{C}$ per $10 \mathrm{~s}$. The samples of $25^{\circ} \mathrm{ng}$ cDNA were analyzed in quadruplicate in parallel with GAPDH controls; standard curves (threshold cycle vs log pg cDNA) were generated by log dilutions of standard cDNA (reverse transcribed mRNA from satellite cells in GM) from $0.1 \mathrm{pg}$ to $100 \mathrm{ng}$. Experimental mRNA starting quantities were then calculated from the standard curves and averaged using SABioscience software as described previously (26). The ratios of marker experimental gene (e.g., VDR, IGF1 and 2, FGF1 and 2, MSTN, and FST mRNA) to that of GAPDH mRNA were computed and normalized with control (untreated) samples as 100\%.

\section{Western blotting and densitometry analyses}

The cell lysates $(50 \mu \mathrm{g}$ protein) were subjected to Western blotting analyses by $4-15 \%$ Tris-HCl PAGE (Bio-Rad) in a running buffer (Tris/glycine/SDS). The proteins were

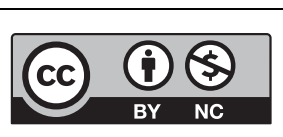

This work is licensed under a Creative Commons Attribution-NonCommercial 4.0 International License. 
A

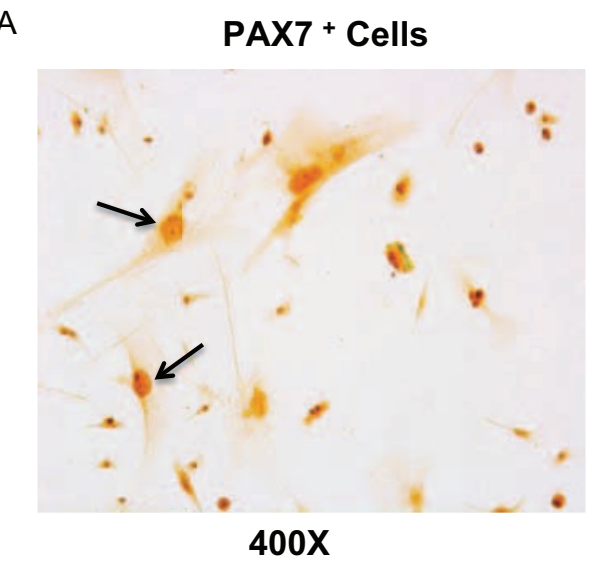

B

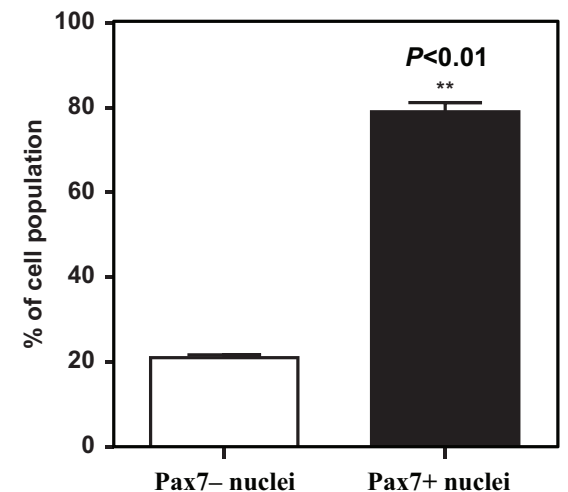

Figure 1

Efficiency in the isolation of primary cultures of satellite cells from skeletal muscle. Once the satellite cells were isolated and prior to starting the culture expansion, the efficiency of the applied technique was tested by the expression of PAX7 by immunocytochemistry (A). Magnification $400 x$. The counting of positive PAX7 nuclei with the Image-Pro software renders an $81 \%$ efficiency $(P<0.01)$ in the isolation of satellite cells by the applied methodology (B).

transferred onto PVDF membranes in a transfer buffer (Tris/ glycine/methanol) using transblot semi-dry apparatus (BioRad). The nonspecific binding was blocked by immersing the membranes into $5 \%$ nonfat dried milk and $0.1 \%(\mathrm{v} / \mathrm{v})$ Tween 20 in PBS for $3 \mathrm{~h}$ at RT. After several washes with the washing buffer (PBS Tween 0.1\%), the membranes were incubated with the primary antibodies for $3 \mathrm{~h}$ at RT or overnight at $4^{\circ} \mathrm{C}$. Primary rabbit polyclonal antibodies from Abcam were used for: VDR (1:1000), IGF1 (1:500), IGF2 (1:500), FGF1 (1:500), FGF2 (1:500) and FST (1:500). The MYC type II (1:1000) was a monoclonal antibody also from Abcam. The MYOD (1:500) and the MYOG (1:500) were both polyclonal rabbit antibodies from Santa Cruz Biotechnology. The rabbit polyclonal MSTN antibody (1:500) and the mouse monoclonal GAPDH antibody (1:5000) were both from Millipore. After several washes with buffer, the membranes were incubated for $3 \mathrm{~h}$ at RT with $1 / 2000$ dilution (anti-mouse) or 1:2000

$\begin{array}{lr}\text { http://www.endocrineconnections.org } & \text { ○ } 2017 \text { The authors } \\ \text { DOI: } 10.1530 / \text { EC-17-0008 } & \text { Published by Bioscientifica Ltd }\end{array}$

A
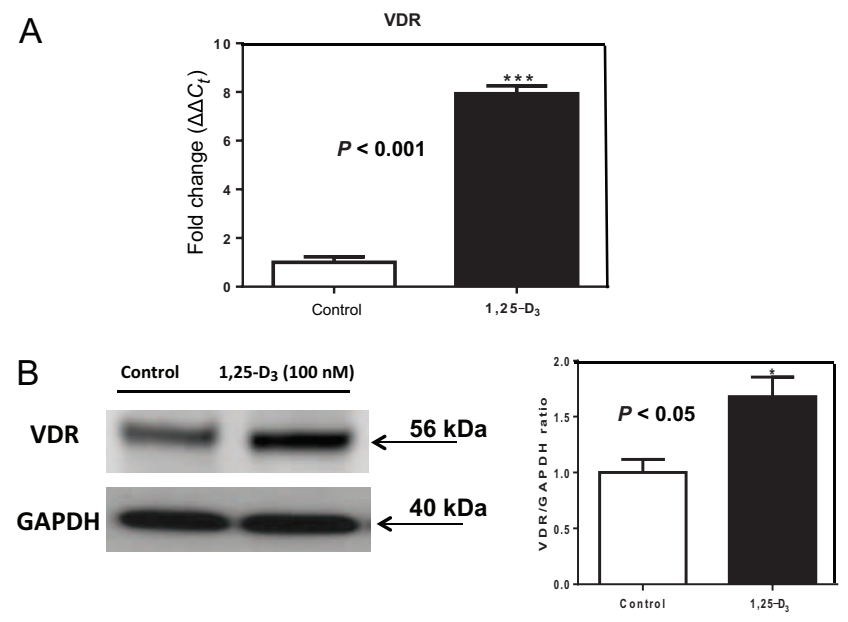

C

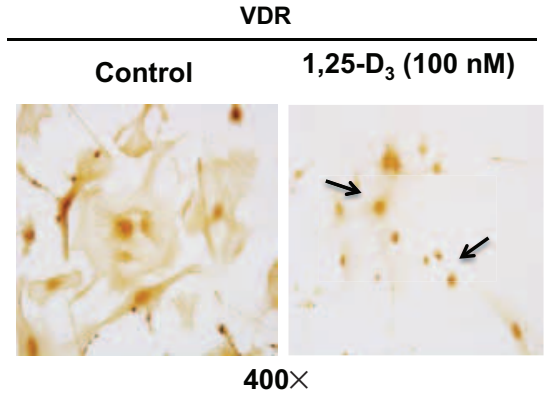

Figure 2

Expression, nuclear translocation and upregulation of steady-state mRNA and protein levels of VDR upon incubation of satellite cells with 1,25- $D_{3}$. Cultures of satellite cells were continuously incubated with or without $1,25-D_{3}(100 \mathrm{nM})$ for 7 days on four-well removable chamber slides and then were subjected to real-time PCR (A); Western blotting with the corresponding densitometric analysis $(B)$ and immunocytochemistry using a rabbit polyclonal antibody for VDR, magnification $400 \times$ (C).

Mean \pm S.E.M. corresponds to experiments done in triplicate, $P<0.001$

(A) and $P<0.05$ (B). Samples and controls were normalized to the GAPDH housekeeping mRNA/protein.

dilution (anti-rabbit) of secondary antibody linked with HRP (Cell Signaling Technology). After several washes, the immunoreactive bands were visualized using the WesternSure PREMIUM chemiluminescent detection system (Li-COR Biotechnology, Lincoln, NE, USA). The scanning of the bands was done with the C-DiGit Blot Scanner (Li-COR Biotechnology) and the images were captured with the Image Studio Software, version 5.2 (Li-COR Biotechnology).

\section{Statistical analysis}

All data are presented as mean \pm S.E.M., and betweengroup differences were analyzed using ANOVA. If the overall ANOVA revealed significant differences, then pair-wise comparisons between groups were performed

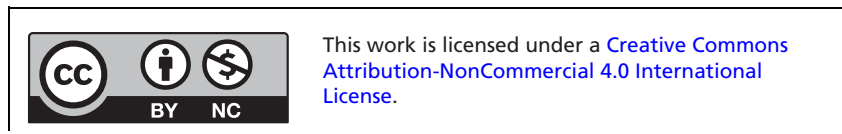


A

Control: No addition of $1,25-\mathrm{D}_{3}(100 \mathrm{nM})$

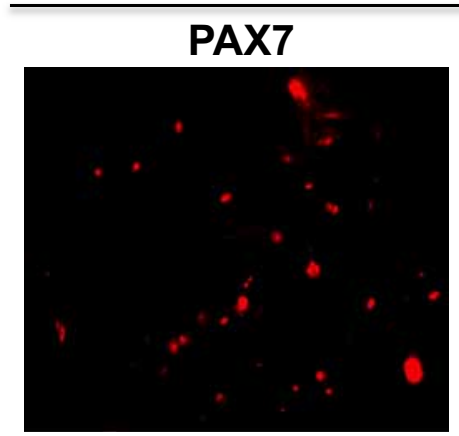

VDR

DAPI
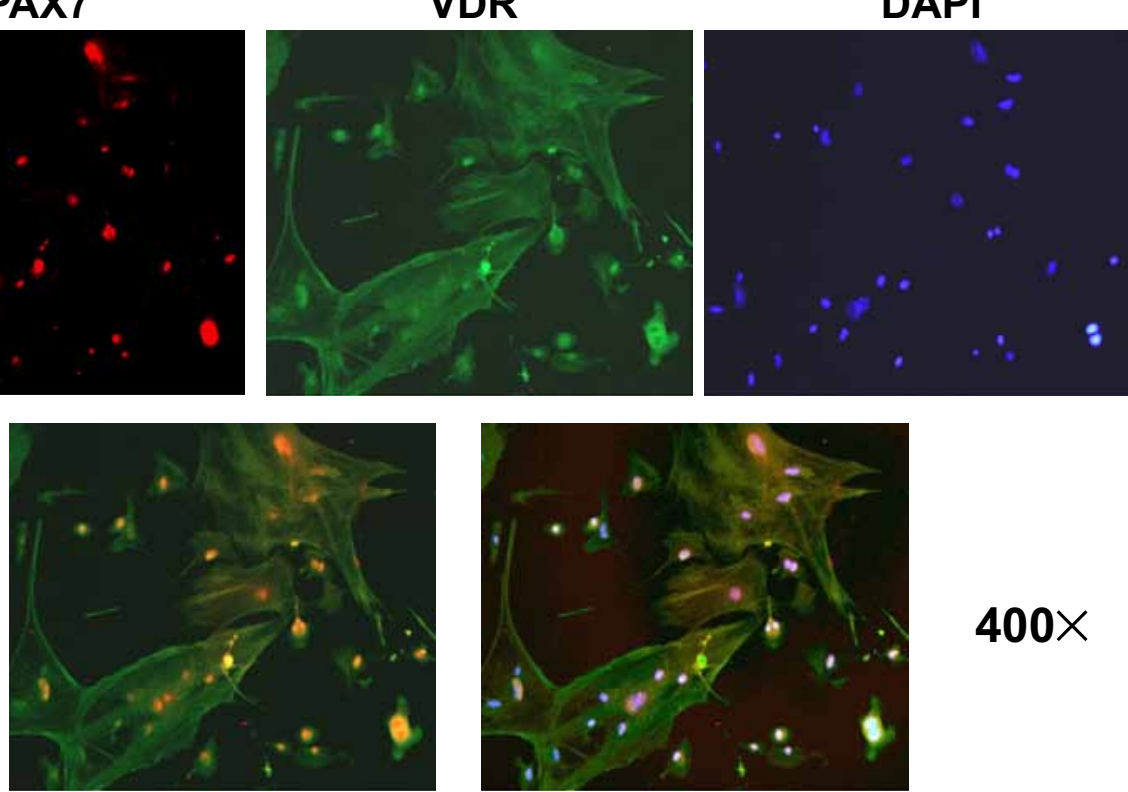

Merge: PAX7 + VDR

Merge: PAX7 + VDR + DAPI

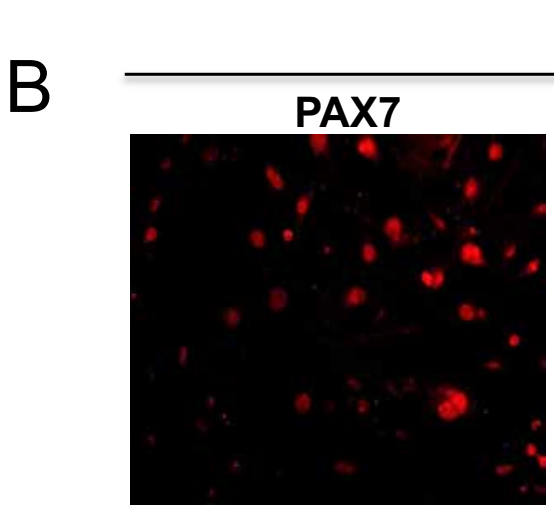

$+1,25-D_{3}(100 \mathrm{nM})$

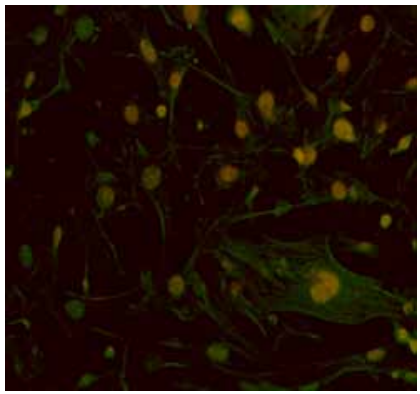

VDR

DAPI

$400 \times$
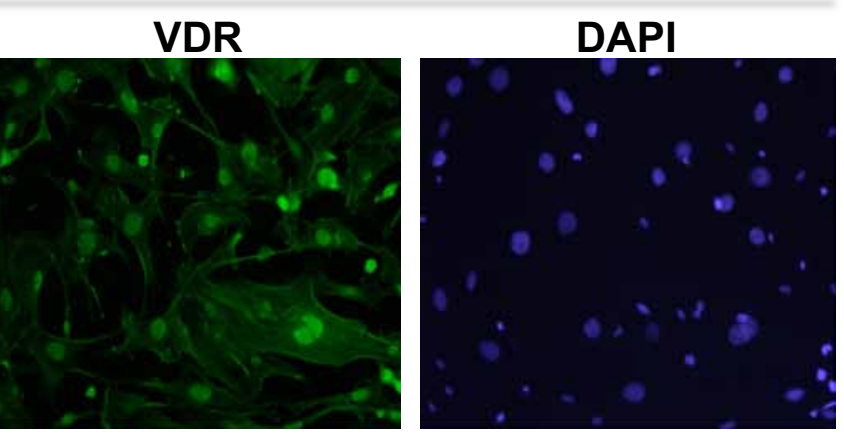

Merge: PAX7 + VDR

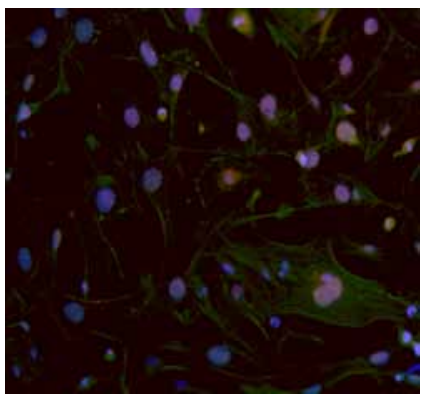

$400 \times$

Figure 3

Co-expression of PAX7 and VDR in primary cultures of satellite cells. The experiment was carried out on primary cultures of satellite cells plated on collagen-coated chamber slides that were continuously incubated with or without $1,25-D_{3}$ for 7 days, (A) no addition of $1,25-D_{3}$ and $(B)$ with $1,25-D_{3}$. After the incubation period, cells were subjected to double immunofluorescence for VDR (FITC, green) and PAX7 (Texas red). The counterstaining was done with DAPI (blue). The 'yellow' VDR/PAX7 merge images were obtained by fusing the red and green filtered pictures, and the 'purple' picture were obtained by merging the VDR/PAX7/DAPI pictures. Magnification 400x.

\begin{tabular}{lr}
\hline http://www.endocrineconnections.org & ○ 2017 The authors \\
DOI: $10.1530 /$ EC-17-0008 & Published by Bioscientifica Ltd
\end{tabular}

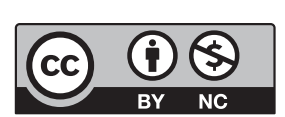

This work is licensed under a Creative Commons Attribution-NonCommercial 4.0 International License. 
Table 1 Differential steady-state mRNA levels of pro- and anti-myogenic growth factors and myogenic markers between 1,25- $D_{3}$ treated and untreated satellite cells.

\begin{tabular}{lllll}
\hline Ref. Seq & Symbol & Description & Fold $\boldsymbol{\Delta}$ \\
\cline { 1 - 1 } NM_007554 & Bmp4 & & Bone morphogenic protein 4 & +2.7 \\
NM_008006 & Fgf2 & Fibroblast growth factor 2 & +2.52 \\
NM_010512 & Igf1 & Insulin-like growth factor 1 & +1.62 \\
NM_010514 & Igf2 & Insulin-like growth factor 2 & +6.01 \\
NM_010834 & MSTN & Myostatin & -2.6 \\
NM_013599 & MMP9 & Matrix metallopeptidase 9 & +3.2 \\
NM_030679 & Myh1 & Myosin, heavy polypeptide 1, & +3.99 \\
NM_009405 & Skeletal muscle adult & +1.93 \\
NM_011620 & Tnni2 & Troponin I, skeletal, fast 2 & +2.2 \\
\hline
\end{tabular}

Total RNA from cells treated as in Fig. 2 for 7 days was subjected to RT real-time PCR by the Skeletal Muscle: Myogenesis \& Myopathy PCR Array, and the ratios between the 1,25- $\mathrm{D}_{3}$-treated and 1,25- $\mathrm{D}_{3}$-untreated cells corrected by GAPDH were calculated for assays performed in triplicate. All experiments were done in triplicates.

by Tukey's multiple comparison test. All comparisons were two-tailed, and $P<0.05$ were considered statistically significant. The in vitro experiments were repeated thrice, and data from representative experiments are shown. Specifically, the $\mathrm{RT}^{2}$ Profiler PCR Arrays were done in triplicates and in some cases further confirmed by qRT-PCR done in triplicates.

\section{Results}

\section{Efficiency in the isolation of primary cultures of satellite cells from skeletal muscle}

To determine the efficiency of the satellite cell isolation from skeletal muscle by the methodology described by Danoviz and Yablonka-Reuveni, the primary cultures were tested for the expression of PAX7 by immunocytochemistry
(Fig. 1A). PAX7 is a unique marker for satellite cells, which is expressed in the nuclei of myogenic progenitor cells during development and thought to be exclusively expressed in satellite cells of mature muscle $(27,28)$. The counting of positive PAX7 nuclei with the Image-Pro software renders an $81 \%$ of efficiency $(P<0.01)$ in the isolation of satellite cells by the applied methodology (Fig. 1B).

\section{Increase expression and nuclear translocation of VDR in satellite cells upon incubation with $1,25-D_{3}$}

To determine whether satellite cells expressed VDR at a basal level and whether its expression and nuclear translocation is induced upon incubating the cells with $1,25-\mathrm{D}_{3}$, real-time PCR, Western blots and immunocytochemistry were carried out after the cells were continuously incubated or not with
A

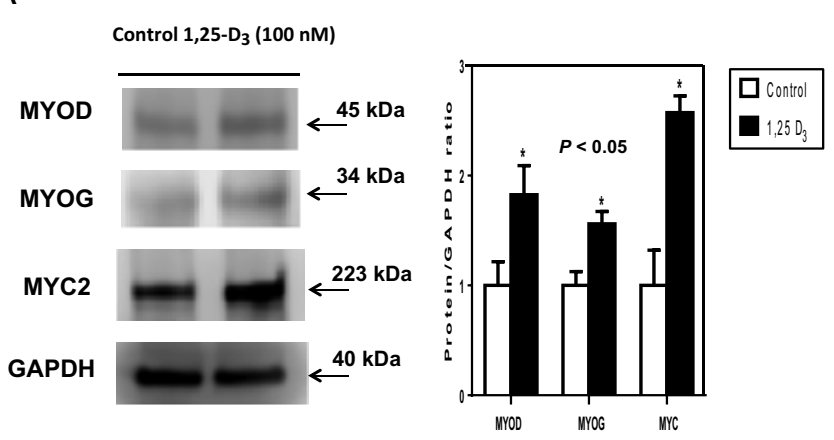

B

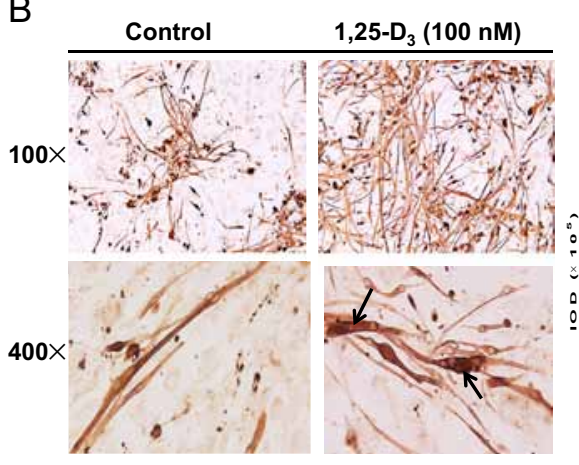

MYC2

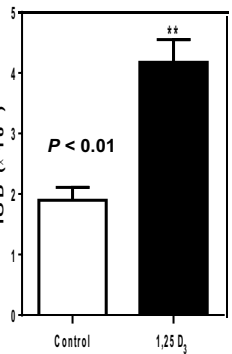

Figure 4

$1,25-D_{3}$ promotes myogenic differentiation in primary cultures of satellite cells. Primary cultures of satellite cells were treated as in Figs 2 and 3. Representative Western blots with the corresponding densitometric analysis ( $\left.{ }^{*}<0.05\right)$ are shown for MYOD, MYOG and MYC type II. Samples and controls were normalized with GAPDH housekeeping gene (A). Panel (B) shows representative immunocytochemistry pictures at $100 \times$ and $400 \times$ magnification of satellite expressing MYC type II with the corresponding image analysis expressing percentage IOD (area $\times$ intensity) for experiments done in triplicate $(* * P<0.01)$. Arrows indicate polynucleated myotubes.

$\begin{array}{lr}\text { http://www.endocrineconnections.org } & \text { ○ } 2017 \text { The authors } \\ \text { DOI: } 10.1530 / \text { EC-17-0008 } & \text { Published by Bioscientifica Ltd }\end{array}$

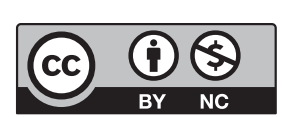

This work is licensed under a Creative Commons Attribution-NonCommercial 4.0 International License. 
A
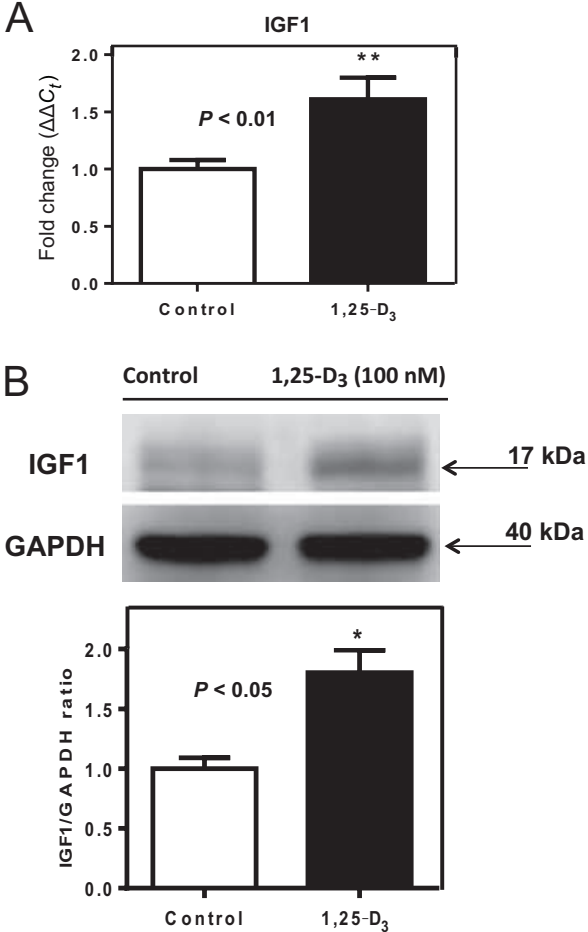

\section{Figure 5}

Upregulation of IGF1 steady-state mRNA and protein levels upon incubation of satellite cells with $1,25-D_{3}$. Primary cultures of satellite cells were incubated as in Fig. 2 for 7 days. Total RNA and whole-protein extracts were isolated for qRT-PCR and Western blottings, respectively. (A) Mean \pm S.E.M. corresponds to experiments done in triplicate for IGF1; $* * P<0.01$. (B) Western blottings with the corresponding densitometric analysis for IGF1; ${ }^{*} P<0.05$. In both cases, real-time PCR and Western blottings, samples and controls were normalized with GAPDH housekeeping gene.

$1,25-\mathrm{D}_{3}(100 \mathrm{nM})$ for 7 days. The dose of $1,25-\mathrm{D}_{3}$ used for these studies was derived from studies published by us and others on the effect of different concentrations of $1,25-\mathrm{D}_{3}$ at 3 and 4 days on the proliferation of $\mathrm{C} 3 \mathrm{H}_{10 \mathrm{~T}_{1 / 2}}$ multipotent cells. In those studies, comparison of $1,25-\mathrm{D}_{3}$ at 10 and $50 \mathrm{nM}$ to controls had no effect, while there was a dosedependent significant decrease in cell proliferation with increasing doses that peaked at $1,25-\mathrm{D}_{3}(100 \mathrm{nM})(22)$. The increased expression of VDR upon incubation with $1,25-\mathrm{D}_{3}$ was demonstrated by real-time PCR (quantitative RT-PCR (qRT-PCR)) (Fig. 2A). VDR mRNA expression was increased by 8 -fold at 7 days, compared with the controls (no $1,25-\mathrm{D}_{3}$ addition). The increased expression of VDR after 1,25-D incubation was further confirmed by Western blot analyses with the corresponding image analysis using wholecell culture homogenates under the same conditions as above. Densitometricanalysis of the bands revealed an increased VDR expression upon incubation with $1,25-\mathrm{D}_{3}$ for 7 days by 1.7 fold (Fig. 2B). Immunocytochemistry studies showed mostly
A
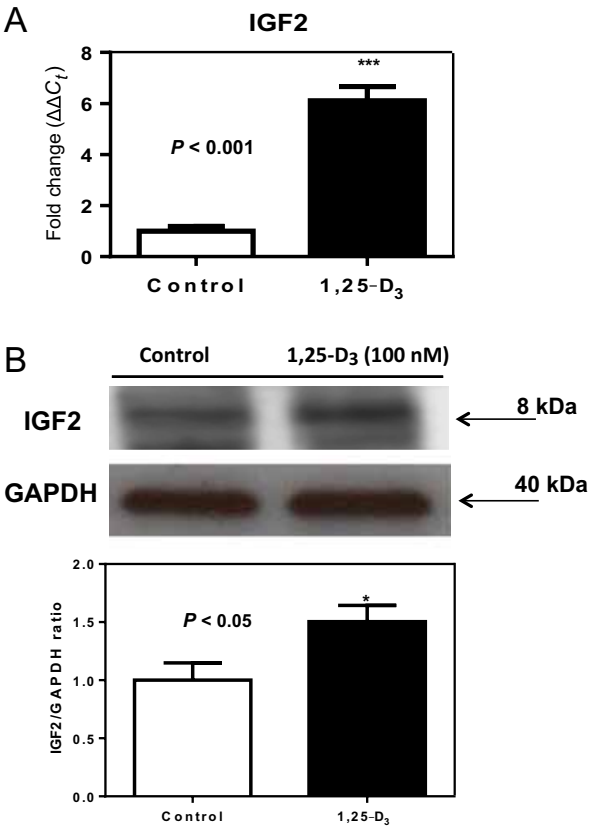

Figure 6

Steady-state mRNA and protein levels upregulation of IGF2 upon incubation of satellite cells with $1,25-D_{3}$. Primary cultures of satellite cells were incubated as in Fig. 2 for 7 days. Total RNA and whole-protein extracts were isolated for qRT-PCR and Western blottings, respectively. (A) Mean \pm S.E.M. corresponds to experiments done in triplicate for IGF2; $* * * P<0.001$. (B) Western blottings with the corresponding densitometric analysis for IGF2; ${ }^{*} P<0.05$. In both cases, real-time PCR and Western blottings, samples and controls were normalized with GAPDH housekeeping gene.

a basal cytoplasmic localization of VDR in the control (no $1,25-\mathrm{D}_{3}$ incubation) compared with a predominant nuclear localization upon continuous incubation of the cells with $1,25-\mathrm{D}_{3}$ for 7 days (Fig. 2C).

\section{Co-expression of PAX7 and VDR in primary cultures of satellite cells}

In order to demonstrate that the isolated satellite cells are PAX7 positive and in addition express VDR, a double immunofluorescence experiment was carried out. Figure 3 shows first (panel A) that satellite cells not incubated with $1,25-\mathrm{D}_{3}$ express PAX7 (red) in the nuclei and express VDR (green) mostly located in the cytoplasm. Upon continuously incubating the satellite cells with $1,25-\mathrm{D}_{3}$ for 7 days (panel B), they still expressed PAX7 (red) in the nuclei, but this time the same cells expressed the VDR (green) mostly in the nuclei, denoting a typical translocation of the VDR receptors to the nuclei. DAPI was utilized to show the nuclear localization. The yellow merge picture denotes the co-expression between PAX7 (red) and VDR (green)

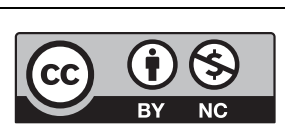

This work is licensed under a Creative Commons Attribution-NonCommercial 4.0 International License. 
A

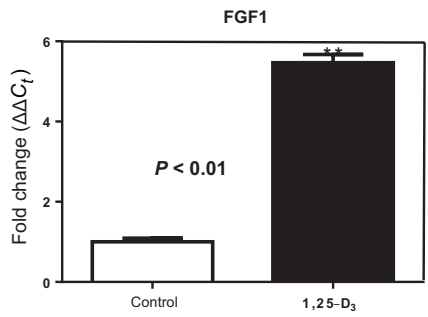

B
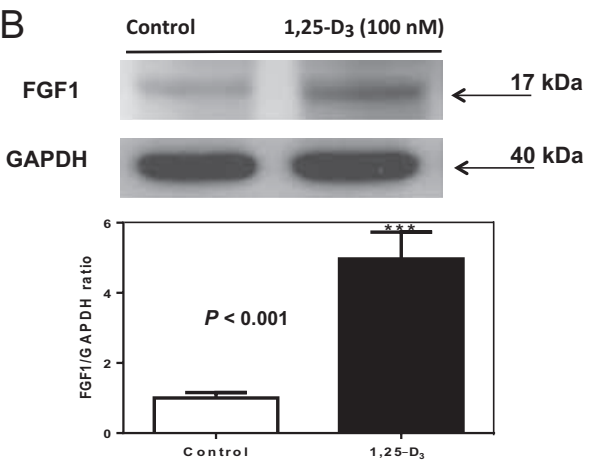

Figure 7

Steady-state mRNA and protein levels upregulation of FGF1 upon incubation of satellite cells with $1,25-D_{3}$. Primary cultures of satellite cells were incubated as in Fig. 2 for 7 days. Total RNA and whole-protein extracts were isolated for qRT-PCR and Western blottings, respectively. (A) Mean \pm S.E.M. corresponds to experiments done in triplicate for FGF1. $* * P<0.01$. (B) Western blottings with the corresponding densitometric analysis for FGF1; $* * * P<0.001$. In both cases, real-time PCR and Western blottings, samples and controls were normalized with GAPDH housekeeping gene.

and the purple cells demonstrate the co-localization among PAX7, VDR and DAPI.

\section{$1,25-D_{3}$ enhances myogenic differentiation in satellite cells by promoting the expression of myogenic markers, myotube formation and by modulating myogenic growth factors}

The effect of $1,25-\mathrm{D}_{3}$ on specific myogenic markers of cell differentiation and growth factors were evaluated at the steady-state mRNA level by RT2 Profiler PCR Array (Skeletal Muscle: Myogenesis \& Myopathy Pathways). Table 1 shows the differential steady-state mRNA levels between $1,25-\mathrm{D}_{3}$ treated (7 days) and untreated cells for determinations done in triplicate after 7 days of continuous incubation with $1,25-\mathrm{D}_{3}$. The PCR array analysis showed an upregulation in the expression of skeletal muscle myogenic markers such as MYH1 $(+3.99)$, Tnni2 (+1.93) and Tnni3 (+2.2). Changes in the expression of pro- and anti-myogenic factors were also observed: upregulation in the expression of IGF1 (+1.62), IGF2 (+6.01) and FGF2 (+2.52), and
A

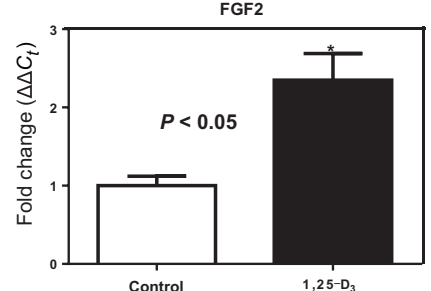

B
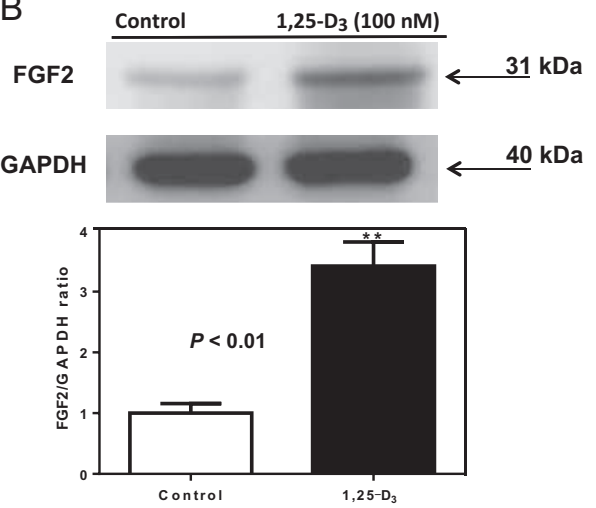

Figure 8

Steady-state mRNA and protein levels upregulation of FGF2 upon incubation of satellite cells with $1,25-D_{3}$. Primary cultures of satellite cells were incubated as in Fig. 2 for 7 days. Total RNA and whole-protein extracts were isolated for qRT-PCR and Western blottings, respectively. (A) Mean \pm S.E.M. corresponds to experiments done in triplicate for FGF2 ${ }^{*} P<0.05$. (B) Western blottings with the corresponding densitometric analysis for FGF2; ${ }^{*} P<0.01$. In both cases, real-time PCR and Western blottings, samples and controls were normalized with GAPDH housekeeping gene.

most importantly a marked downregulation of MSTN (-2.6). Continuous incubation of satellite cells with $1,25-\mathrm{D}_{3}$ also increased the expression of BMP4 (+2.7), a positive marker of myotube formation/maturation (29). In addition, MMP9 was upregulated (+3.2); MMP9 is a marker of myogenic cell migration and engraftment (30) that is also known to coordinate and affect wound repair.

The pro-myogenic effect of vitamin D on satellite cells was further demonstrated by the increased expression of myogenic markers such as MYOD, MYOG and MYC type II by Western blots with the corresponding densitometric analysis upon incubation of satellite cells with $1,25-\mathrm{D}_{3}$ (Fig. $4 \mathrm{~A}$ ). In addition we were able to demonstrate that $1,25-\mathrm{D}_{3}$ induced myotube formation showing polynucleated myotube formation and increased expression of MYC type II by immunocytochemistry with the corresponding image analysis expressing percentage IOD (area $\times$ intensity) for experiments done in triplicate $\left({ }^{* *} P<0.01\right)$ (Fig. 4B).

The increased expression of IGF1, IGF2, FGF1 and FGF2 after $1,25-\mathrm{D}_{3}$ incubation was further confirmed

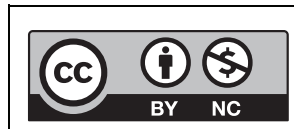

This work is licensed under a Creative Commons Attribution-NonCommercial 4.0 International License. 

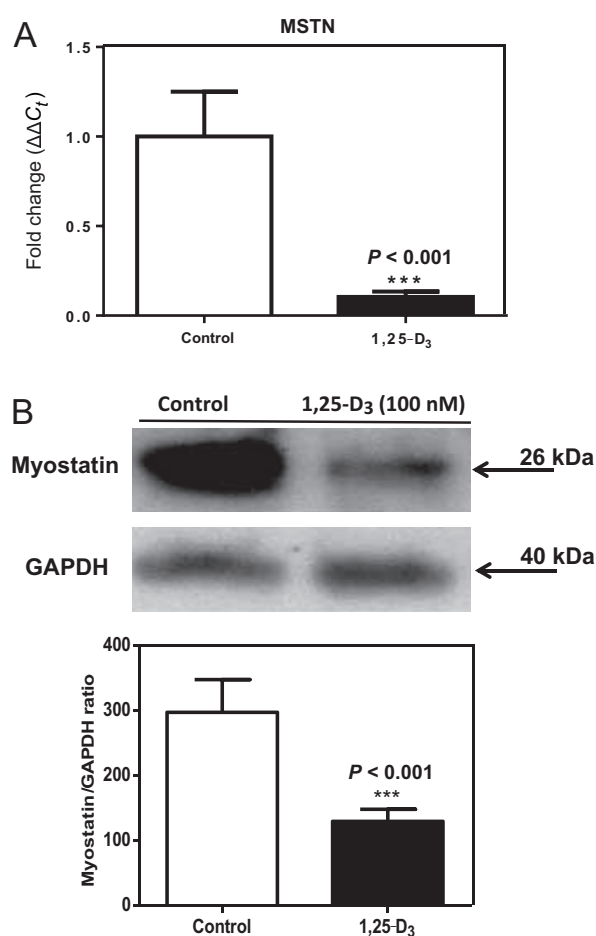

\section{Figure 9}

$1,25-D_{3}$ downregulates the expression of MSTN in satellite cells. Cultures of satellite cells were treated as in Fig. 2 for 7 days. Total RNA and whole-cell protein extracts were isolated for GRT-PCR and Western blottings, respectively. (A) Mean \pm S.E.M. corresponds to experiments done in triplicate for MSTN; $* * * P<0.001$. (B) MSTN Western blottings with the corresponding densitometric analysis; $* * * P<0.01$. In both cases, qRT-PCR (A) and Western blottings (B), samples and controls were normalized with GAPDH housekeeping gene.

at 7 days by quantitative real-time PCR, and at the protein level by Western blots with the corresponding densitometric analysis. Figure $5 \mathrm{~A}$ shows the +1.5 -fold increase in the expression of IGF1 by real-time PCR compared with the control $(P<0.01)$, and Fig. 5B shows a similar pattern by Western blot compared with the control $(P<0.05)$. Figure $6 \mathrm{~A}$ shows a +4.0 -fold increase of IGF2 mRNA expression by real-time PCR upon incubating the cells with $1,25-\mathrm{D}_{3}$ compared to the control with a similar pattern of expression at the protein level by Western blot (Fig. 6B). The increased expression of FGF1 (+3.9fold) upon $1,25-\mathrm{D}_{3}$ incubation was also confirmed at the steady-state mRNA level by real-time PCR (Fig. 7A) and at the protein level by Western blots with the corresponding densitometric analysis (Fig. 7B). Similarly, an increased expression of FGF2 was confirmed by real-time PCR (+2.3fold) (Fig. 8A) and by Western blot analysis (Fig. 8B).

Because the PCR arrays showed a decreased expression of MSTN upon incubating the cells with 1,25- $\mathrm{D}_{3}$, and because MSTN is a known negative regulator of skeletal

$$
\begin{aligned}
& \text { http://www.endocrineconnections.org } \\
& \text { DOI: 10.1530/EC-17-0008 }
\end{aligned}
$$

A

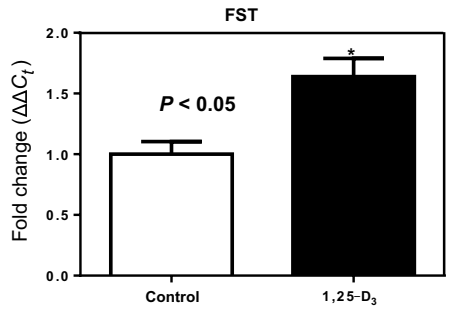

B
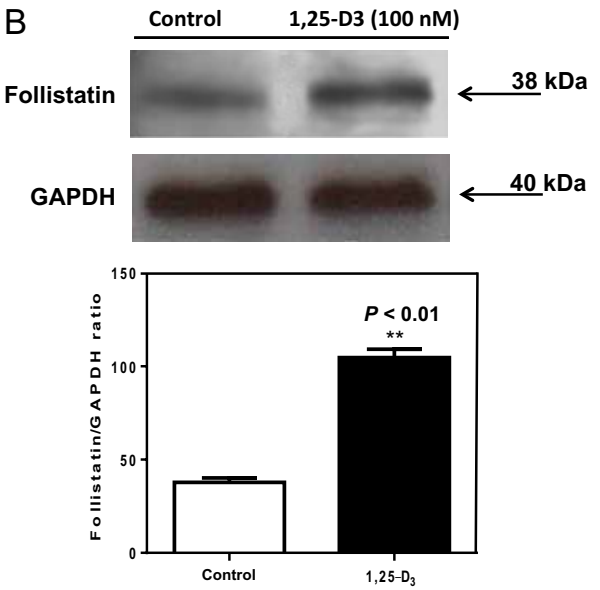

\section{Figure 10}

Steady-state mRNA and protein upregulation levels of FST expression upon incubation of satellite cells with $1,25-D_{3}$. Cultures of satellite cells were incubated as in Fig. 2 for 7 days. Total RNA and whole-protein extracts were isolated for qRT-PCR and Western blottings. (A)

Mean \pm S.E.M. corresponds to experiments done in triplicate; ${ }^{*} P<0.05$. (B) FST Western blottings with the corresponding densitometric analysis; $* * P<0.01$. In both cases, qRT-PCR (A) and Western blottings (B), samples and controls were normalized with GAPDH housekeeping gene.

muscle mass, we further confirmed the PCR arrays by quantitative real-time PCR. The real-time PCR for MSTN performed at 7 days of continuous incubation with $1,25-\mathrm{D}_{3}$ showed a remarkable decrease in MSTN expression by 5 -fold, compared with the control $(P<0.001)$ (Fig. 9A). The remarkable decreased expression of MSTN at the protein level was shown by Western blotting, with the respective densitometric analysis (Fig. 9B).

\section{$1,25-D_{3}$ increases FST expression in primary cultures of skeletal muscle satellite cells}

To determine whether FST, which inhibits MSTN activity in vitro and in vivo, is involved in the mechanism by which $1,25-\mathrm{D}_{3}$ promotes muscle growth, we investigated FST expression in primary cultures of skeletal muscle derived satellite cells, with and without $1,25-\mathrm{D}_{3}$ incubation. Real-time qPCR revealed that after 7 days of continuous incubation with $1,25-\mathrm{D}_{3}$, FST expression was increased by 1.7 -fold compared with controls $(P<0.05)$ (Fig. 10A).

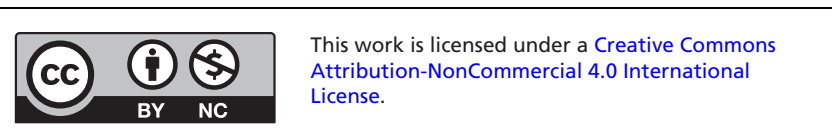


Because MSTN expression was substantially downregulated at day 7 by $1,25-\mathrm{D}_{3}$, we determined the expression of FST at the protein level by Western blotting. Figure 10B shows that the expression of FST was significantly upregulated $(P<0.01)$ compared with controls, suggesting that $1,25-\mathrm{D}_{3}$ promotes myogenic differentiation by inhibiting MSTN activity, possibly through an increase in FST expression.

\section{Discussion}

The data presented in this manuscript demonstrate that VDR is expressed in skeletal muscle satellite cells that are responsible for restoring muscle mass after injury. Furthermore, the addition of $1,25-\mathrm{D}_{3}$ to satellite cell primary cultures enhances myogenic differentiation through an increased expression and nuclear translocation of VDR; triggering an increase in the expression of myogenic markers, myotube formation, and a modulation of pro- and antimyogenic factors. The increase in VDR expression, to some extent, is expected, because it is known that $1,25-\mathrm{D}_{3}$ auto-regulates the expression of the VDR gene through intronic and upstream enhancers (32). In this manuscript, we also demonstrated that the $1,25-\mathrm{D}_{3}$ effect on skeletal muscle satellite cells involves: an increased expression of known pro-myogenic skeletal muscle markers such as (1) MYOD, (2) MYOG, (3) MYC type II, (4) muscle troponin I and troponin T, (5) MYH1 (myosin heavy chain I); and growth factors such as (6) IGF1 and 2, (7) FGF1 and 2, (8) BMP4 and (9) MMP9. Furthermore, exposure of satellite cells to $1,25-\mathrm{D}_{3}$ increases myotube formation. It also upregulates the expression of FST (a MSTN inhibitor) (33); even more, we showed that $1,25-\mathrm{D}_{3}$ downregulates MSTN expression, the most important negative regulator of muscle mass (34). Myogenesis of skeletal muscle cells is a highly ordered and sequential process: it starts with a period of proliferation followed by a differentiation process that generates myoblasts from mesodermal stem cells. Satellite cells are maintained in a quiescent state and upon requirement are activated to proliferate and fuse with other cells to form or repair myofibers. In addition, they are able to self-renew and replenish the stem pool. In this study, we were able to demonstrate that satellite cells express the VDR receptor, making them the main target for vitamin D. Satellite cells were characterized by the expression of PAX7, which is considered the main defining factor for this cell type $(27,35)$. The increase in expression of well-known myogenic markers such as MYOD, MYOG,
MYC type II, MYH1 and muscle troponin I and T, upon incubation of satellite cells with $1,25-\mathrm{D}_{3}$, is a clear indication of the pro-myogenic effect of vitamin $\mathrm{D}$ in this primary culture cell system. We also demonstrated that the addition of $1,25-\mathrm{D}_{3}$ induced gene expressions of pathways involved in myogenic differentiation, such as IGF, FGF and TGF- $\beta$-related signaling pathways.

$1,25-\mathrm{D}_{3}$ increases the expression of IGF1 and IGF2, which indicates that IGFs play an important role in pushing muscle differentiation in the proposed system. It has been shown that the IGF signaling pathway plays a key role in the regulation of skeletal muscle growth and differentiation. Both IGF1 and 2 are locally expressed in muscle cells contributing to the regulation of skeletal muscle growth, differentiation, and also maintaining adult muscle tissue homeostasis (36). Moreover, IGFs plays a critical role in adult muscle survival, regeneration and hypertrophy $(37,38,39)$. Even more, it has been recently described that IGF1 suppresses MSTN signaling pathway during myogenic differentiation, adding one more mechanistic indication to the inhibition of MSTN by vitamin D (40). At the same time, it has been shown that IGF2 inhibition leads to a reduced expression of MYOD target genes, which suggests that IGF2 is also essential for amplifying and maintaining MYOD efficacy (41). Regarding the increase expression of FGF1 and FGF-2 by 1,25-D3, it has been previously described that both proteins are present in proliferating skeletal muscle cells, but are undetectable after terminal differentiation (42). The same publication reports that transient transfection of cells with FGF1 or FGF2 expression constructs exerted a global effect on myoblast DNA synthesis indicating that production of FGF1 and FGF2 by skeletal muscle cells may act as a paracrine and autocrine regulator of skeletal muscle development in vivo.

We also demonstrated the increased expression of Bmp4 upon incubation of satellite cells with 1,25- $\mathrm{D}_{3}$, consistent with the concept that Bmp4 expressed in myoblasts has a positive role in myotube formation/ maturation through MYOG expression (29).

Concerning the increased expression of MMP9 induced by vitamin $\mathrm{D}$ incubation, it has been shown that overexpression of MMP family members, especially MMP9, improves myogenic cell migration and engraftment (30). As it was mentioned earlier in the text, it also coordinates wound repair since deficient MMP9 mice were unable to remove the fibrinogen matrix during wound healing (31).

Regarding the TGF- $\beta$ signaling pathway involvement in myogenic differentiation promoted by vitamin $\mathrm{D}$, our study in primary cultures of satellite cells confirms our previous results obtained on the C2C12 myoblast

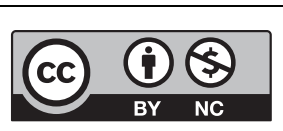
This work is licensed under a Creative Commons
Attribution-NonCommercial 4.0 International License. 
cell line (11): that $1,25-\mathrm{D}_{3}$ administration to skeletal muscle cells reduced the expression of MSTN, the most relevant negative regulator of muscle mass known to date (34). Even more, we were also able to confirm in this highly relevant cell system that FST, which is a MSTN-binding protein that can inhibit MSTN activity in vitro and promote muscle growth in vivo (33) increases upon incubation with $1,25-\mathrm{D}_{3}$. It has been shown that FST antagonizes MSTN by a direct protein interaction, preventing MSTN from executing its inhibitory effect on muscle development (43).

These sets of results reinforce the pro-myogenic effect of $1,25-\mathrm{D}_{3}$ on skeletal muscle differentiation via regulation of different pathways and the decreased MSTN expression at the steady-state mRNA and protein level, by possibly inhibiting MSTN activity through an increase in FST and IGF1 expression.

In summary, we showed that satellite cells expressed VDR and that addition of $1,25-\mathrm{D}_{3}$ to satellite cells induces increased expression of: (i) MYOD, (ii) MYOG, (iii) MYC type II, (iv) muscle troponin I and T, (v) MYH1, (vi) IGF1 and 2, (vii) FGF1 and 2, (viii) BMP4, (ix) MMP9 and (x) FST. It also induces a decrease expression of MSTN. In conclusion, vitamin $\mathrm{D}$ exerts a clear pro-myogenic effect on satellite cells in charge of muscle reconstitution after muscle injury or muscle waste. We believe that this study provides a mechanistic justification for vitamin D replenishment in muscle waste conditions such as AIDS, cancer and renal failure, characterized by loss of muscle mass, and also in vitamin D deficient elderly adults who have an age-related loss of muscle mass and strength, and an increased rate of falls. The study even opens the door for an emerging potential role of therapies directed to trigger select vitamin D regulated muscle pathways in the treatment of adverse muscle conditions.

\section{Declaration of interest}

The authors declare that there is no conflict of interest that could be perceived as prejudicing the impartiality of the research reported.

\section{Funding}

This work was supported by NIH-National Institute on Minority Health and Health Disparities (NIH-NIMHD) grant 5U54MD007598-06 and NIH-NCATS 5UL1TR000124.

\section{References}

1 Holick MF. Vitamin D deficiency. New England Journal of Medicine 2007357 266-281. (doi:10.1056/NEJMra070553)
2 Holick MF \& Chen TC. Vitamin D deficiency: a worldwide problem with health consequences. American Journal of Clinical Nutrition 2008 87 1080S-1086S.

3 Holick MF. The role of vitamin D for bone health and fracture prevention. Current Osteoporosis Reports 20064 96-102. (doi:10.1007/ s11914-996-0028-z)

4 Tieland M, Brouwer-Brolsma EM, Nienaber-Rousseau C, van Loon LJ $\&$ De Groot LC. Low vitamin D status is associated with reduced muscle mass and impaired physical performance in frail elderly people. European Journal of Clinical Nutrition 201367 1050-1055. (doi:10.1038/ejcn.2013.144)

5 Iolascon G, de Sire A, Calafiore D, Moretti A, Gimigliano R \& Gimigliano F. Hypovitaminosis D is associated with a reduction in upper and lower limb muscle strength and physical performance in post-menopausal women: a retrospective study. Aging Clinical and Experimental Research 201521 (Supplement 1) S23-S30. (doi:10.1007/ s40520-015-0405-5)

6 Tomlinson PB, Joseph C \& Angioi M. Effects of vitamin D supplementation on upper and lower body muscle strength levels in healthy individuals. A systematic review with meta-analysis. Journal of Science and Medicine in Sport 201518 575-580. (doi:10.1016/j. jsams.2014.07.022)

7 Olsson K, Saini A, Strömberg A, Alam S, Lilja M, Rullman E \& Gustafsson T. Evidence for vitamin D receptor expression and direct effects of $1 \alpha, 25(\mathrm{OH}) 2 \mathrm{D} 3$ in human skeletal muscle precursor cells. Endocrinology 2016157 98-111. (doi:10.1210/en.2015-1685)

8 Bouillon R, Bischoff-Ferrari H \& Willett W. Vitamin D and health: perspectives from mice and man. Journal of Bone and Mineral Research 200823 974-979. (doi:10.1359/jbmr.080420)

9 Endo I, Inoue D, Mitsui T, Umaki Y, Akaike M, Yoshizawa T, Kato S \& Matsumoto T. Deletion of vitamin D receptor gene in mice results in abnormal skeletal muscle development with deregulated expression of myoregulatory transcription factors. Endocrinology 2003144 5138-5144. (doi:10.1210/en.2003-0502)

10 Holick MF. Vitamin D: evolutionary, physiological and health perspectives. Current Drug Targets 201112 4-18. (doi:10.2174/138945 011793591635)

11 Garcia LA, King KK, Ferrini MG, Norris KC \& Artaza JN. 1,25(OH)2vitamin D3 stimulates myogenic differentiation by inhibiting cell proliferation and modulating the expression of promyogenic growth factors and myostatin in C2C12 skeletal muscle cells. Endocrinology 2011152 2976-2986. (doi:10.1210/en.2011-0159)

12 Garcia LA, Ferrini MG, Norris KC \& Artaza JN. 1,25(OH)(2) vitamin $\mathrm{D}(3)$ enhances myogenic differentiation by modulating the expression of key angiogenic growth factors and angiogenic inhibitors in $\mathrm{C}(2) \mathrm{C}(12)$ skeletal muscle cells. Journal of Steroid Biochemistry and Molecular Biology 2013133 1-11. (doi:10.1016/j. jsbmb.2012.09.004)

13 Girgis CM, Clifton-Bligh RJ, Mokbel N, Cheng K \& Gunton JE. Vitamin D signaling regulates proliferation, differentiation, and myotube size in C2C12 skeletal muscle cells. Endocrinology $2014 \mathbf{1 5 5}$ 347-357. (doi:10.1210/en.2013-1205)

14 Van der Meijden K, Bravenboer N, Dirks NF, Heijboer AC, den Heijer M, de Wit GM, Offringa C, Lips P \& Jaspers RT. Effects of 1,25(OH)2 D3 and 25(OH)D3 on C2C12 myoblast proliferation, differentiation, and myotube hypertrophy. Journal of Cellular Physiology 2016231 2517-2528. (doi:10.1002/jcp.25388)

15 Taylor WE, Bhasin S, Artaza J, Byhower F, Azam M, Willard DH Jr, Kull FC Jr \& Gonzalez-Cadavid N. Myostatin inhibits cell proliferation and protein synthesis in C2C12 muscle cells. American Journal of Physiology: Endocrinology and Metabolism 2001280 E221-E228.

16 Artaza JN, Bhasin S, Mallidis C, Taylor W, Ma K \& GonzalezCadavid NF. Endogenous expression and localization of myostatin and its relation to myosin heavy chain distribution in $\mathrm{C} 2 \mathrm{C} 12$ skeletal muscle cells. Journal of Cellular Physiology 2002190 170-179. (doi:10.1002/jcp.10044)

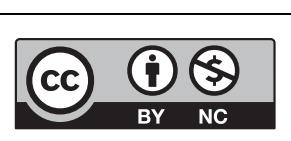

This work is licensed under a Creative Commons Attribution-NonCommercial 4.0 International License. 
17 Musaro A \& Barberi L. Isolation and culture of mouse satellite cells. Methods in Molecular Biology 2010633 101-111. (doi:10.1007/978-159745-019-5_8)

18 Danoviz ME \& Yablonka-Reuveni Z. Skeletal muscle satellite cells: background and methods for isolation and analysis in primary culture system. Methods in Molecular Biology 2011798 21-52. (doi:10.1007/978-1-61779-343-1_2)

19 Barbosa EM, Nonogaki S, Katayama ML, Folgueira MA, Alves VF \& Brentani MM. Vitamin D3 modulation of plasminogen activator inhibitor type-1 in human breast carcinomas under organ culture. Virchows Archiv 2004444 175-182. (doi:10.1007/s00428-003-0929-5)

20 Cardús A, Parisi E, Gallego C, Aldea M, Fernández E \& Valdivielso JM 1,25-Dihydroxyvitamin D3 stimulates vascular smooth muscle cell proliferation through a VEGF-mediated pathway. Kidney International 200669 1377-1384. (doi:10.1038/sj.ki.5000304)

21 Artaza JN \& Norris KC. Vitamin D reduces the expression of collagen and key profibrotic factors by inducing an antifibrotic phenotype in mesenchymal multipotent cells. Journal of Endocrinology 2009200 207-221. (doi:10.1677/JOE-08-0241)

22 Artaza JN, Sirad F, Ferrini MG \& Norris KC. 1,25(OH)2vitamin D3 inhibits cell proliferation by promoting cell cycle arrest without inducing apoptosis and modifies cell morphology of mesenchymal multipotent cells. Journal of Steroid Biochemistry and Molecular Biology 2010119 73-83. (doi:10.1016/j.jsbmb.2010.01.001)

23 Khanna-Jain R, Vuorinen A, Sándor GK, Suuronen R \& Miettinen S. Vitamin D(3) metabolites induce osteogenic differentiation in human dental pulp and human dental follicle cells. Journal of Steroid Biochemistry and Molecular Biology 2010122 133-141. (doi:10.1016/j. jsbmb.2010.08.001)

24 Ramirez AM, Wongtrakool C, Welch T, Steinmeyer A, Zügel U \& Roman J. Vitamin D inhibition of pro-fibrotic effects of transforming growth factor beta1 in lung fibroblasts and epithelial cells. Journal of Steroid Biochemistry and Molecular Biology 2010118 142-150. (doi:10.1016/j.jsbmb.2009.11.004)

25 Hlaing SM, Garcia LA, Kovanecz I, Martinez RA, Shah S, Artaza JN \& Ferrini MG. Sildenafil promotes neuroprotection of the pelvic ganglia neurones after bilateral cavernosal nerve resection in the rat. BJU International 2013111 159-170. (doi:10.1111/j.1464410X.2012.11278.x)

26 Hlaing SM, Garcia LA, Contreras JR, Norris KC, Ferrini MG \& Artaza JN. 1,25-Vitamin D3 promotes cardiac differentiation through modulation of the WNT signaling pathway. Journal of Molecular Endocrinology 201453 303-317. (doi:10.1530/JME-14-0168)

27 Seale P, Sabourin LA, Girgis-Gabardo A, Mansouri A, Gruss P \& Rudnicki MA. Pax7 is required for the specification of myogenic satellite cells. Cell 2000102 777-786. (doi:10.1016/S0092-8674(00)00066-0)

28 Kuang S \& Rudnicki MA. The emerging biology of satellite cells and their therapeutic potential. Trends in Molecular Medicine 200814 82-91. (doi:10.1016/j.molmed.2007.12.004)

29 Umemoto T, Furutani Y, Murakami M, Matsui T \& Funaba M. Endogenous Bmp4 in myoblasts is required for Myotube formation in C2C12 cells. Biochimica et Biophysica Acta 20111810 1127-1135. (doi:10.1016/j.bbagen.2011.09.008)

30 Morgan J, Rouche A, Bausero P, Houssaïni A, Gross J, Fiszman MY \& Alameddine HS. MMP-9 overexpression improves myogenic cell migration and engraftment. Muscle and Nerve 201042 584-595. (doi:10.1002/mus.21737)

31 Mohan R, Chintala SK, Jung JC, Villar WV, McCabe F, Russo LA, Lee Y, McCarthy BE, Wollenberg KR, Jester JV, et al. Matrix metalloproteinase gelatinase B (MMP-9) coordinates and effects epithelial regeneration. Journal of Biological Chemistry 2001277 2065-2072. (doi:10.1074/jbc. M107611200)

32 Pike JW \& Meyer MB. The vitamin D receptor: new paradigms for the regulation of gene expression by 1,25-dihydroxyvitamin $\mathrm{D}(3)$. Endocrinology and Metabolism Clinics of North America 201039 255-269. (doi:10.1016/j.ecl.2010.02.007)

33 Amthor H, Nicholas G, McKinnell I, Kemp CF, Sharma M, Kambadur R $\&$ Patel K. Follistatin complexes myostatin and antagonises myostatinmediated inhibition of myogenesis. Developmental Biology 2004270 19-30. (doi:10.1016/j.ydbio.2004.01.046)

34 Lee SJ. Regulation of muscle mass by myostatin. Annual Review of Cell and Developmental Biology 200420 61-86. (doi:10.1146/annurev. cellbio.20.012103.135836)

35 Lepper C, Partridge TA \& Fan CM. An absolute requirement for Pax7-positive satellite cells in acute injury induced skeletal muscle regeneration. Development 2011138 3639-3646. (doi:10.1242/ dev.067595)

36 Florini JR, Ewton DZ, Magri KA \& Mangiacapra FJ. IGFs and muscle differentiation. Advances in Experimental Medicine and Biology 1993 343 319-326. (doi:10.1007/978-1-4615-2988-0_31)

37 Florini JR, Magri KA, Ewton DZ, James PL, Grindstaff K \& Rotwein PS. Spontaneous differentiation of skeletal myoblasts is dependent upon autocrine secretion of insulin-like growth factor-II. Journal of Biological Chemistry 1991266 15917-15923.

38 Lawlor MA \& Rotwein P. Insulin-like growth factor-mediated muscle cell survival: central roles for Akt and cyclin-dependent kinase inhibitor p21. Molecular and Cellular Biology 200023 8983-8995. (doi:10.1128/MCB.20.23.8983-8995.2000)

39 Jiao S, Ren H, Li Y, Zhou J, Duan C \& Lu L. Differential regulation of IGF-I and IGF-II gene expression in skeletal muscle cells. Molecular and Cellular Biochemistry 2013373 107-113. (doi:10.1007/s11010012-1479-4)

40 Retamales A, Zuloaga R, Valenzuela CA, Gallardo-Escarate C, Molina A \& Valdés JA. Insulin-like growth factor-1 suppresses the Myostatin signaling pathway during myogenic differentiation. Biochemical and Biophysical Research Communications 2015464 596-602. (doi:10.1016/j.bbrc.2015.07.018)

41 Wilson EM \& Rotwein P. Control of MyoD function during initiation of muscle differentiation by an autocrine signaling pathway activated by insulin-like growth factor-II. Journal of Biological Chemistry 2006 281 29962-29971. (doi:10.1074/jbc.M605445200)

42 Hannon K, Kudla AJ, McAvoy MJ, Clase KL \& Olwin BB. Differentially expressed fibroblast growth factors regulate skeletal muscle development through autocrine and paracrine mechanisms. Journal of Cell Biology 1996132 1151-1159. (doi:10.1083/ jcb.132.6.1151)

43 Lee SJ, Lee YS, Zimmers TA, Soleimani A, Matzuk MM, Tsuchida K, Cohn RD \& Barton ER. Regulation of muscle mass by follistatin and activins. Molecular Endocrinology 201024 1998-2008. (doi:10.1210/ me.2010-0127)

Received in final form 13 January 2017

Accepted 7 February 2017

Accepted Preprint published online 7 February 2017 http://www.endocrineconnections.org

DOI: 10.1530/EC-17-0008
(C) 2017 The authors Published by Bioscientifica Ltd

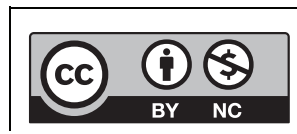

This work is licensed under a Creative Commons Attribution-NonCommercial 4.0 International License. 